\title{
Emotional intelligence of Saudi children in the basic education program
}

\author{
Manal F. Alharbi, RN, PhD.
}

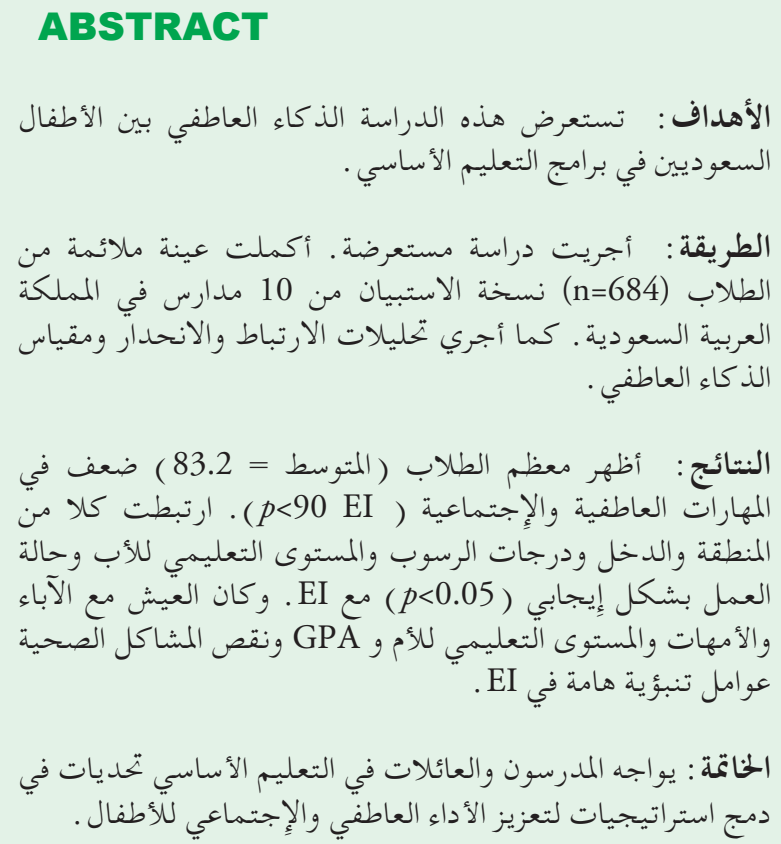

Objectives: To explores emotional intelligence (EI) among Saudi children in basic education programs.

Methods. A cross-sectional study design was utilized. A convenience sample of students $(n=684)$ from 10 schools in Saudi Arabia completed the BarOn Emotional Quotient Inventory-Youth Version. Correlation and regression analyses were conducted.

Results. Most students (mean 83.2) showed poor emotional and social skills ( $p<90 \mathrm{EI}$ ). Region, income, failing grades, father's educational level, and working status correlated positively $(p<0.05)$ with EI. Living with parents, mother's educational level, grade point average, and a lack of health problems were significant predictors of EI.

Conclusions. Basic education teachers and families face challenges in incorporating strategies to enhance children's emotional and social functioning.

Saudi Med J 2018; Vol. 39 (6): 615-621 doi: 10.15537/smj.2018.6.22141
From the Department of Maternity and Child Health Nursing, College of Nursing, King Saud University, Riyadh, Kingdom of Saudi Arabia.

Received 25th February 2018. Accepted 16th May 2018.

Address correspondence and reprint request to: Dr. Manal F. Alharbi, Assistant Professor, Department of Maternity and Child Health Nursing, College of Nursing, King Saud University, Riyadh, Kingdom of Saudi Arabia.E-mail:maalwahbi@ksu.edu.sa ORCID ID: orcid.org/0000-0001-6630-7476

$\mathrm{E}$ motions play a significant role in social and written communications, information processing, cognitive processes, critical thinking skills, personality functions, and physical and mental health. They are an integral part of daily human functioning and are necessary for survival. ${ }^{1}$ One facet of nonverbal intelligence is emotional intelligence (EI). ${ }^{2}$ It is one of the most frequently scrutinized concepts in both social and scientific knowledge. ${ }^{3,4}$ Emotional intelligence is the ability of an individual to express himself or herself, understand and relate to emotions and feelings in others, and cope with the daily stressors and challenges of life. ${ }^{5}$ It is the ability to use emotions effectively to be productive. ${ }^{6}$ Study on EI has revealed relevant positive outcomes. Emotional intelligence has been associated with life satisfaction, marital and work satisfaction, happiness, health, academic achievement, quality of relationships, and leadership potential., ${ }^{3,-9}$ A study in the Middle East showed that EI had a very strong relationship with skills and performance outcomes among 418 leaders. A prediction level of $58 \%$ of the variation was found in critical professional and personal success factors, such as effectiveness, influence, relationships, and career status, using scores from the six second emotional intelligence (SEI), or Six Second Emotional Intelligence Assessment. ${ }^{10}$ Moreover, negative childhood experiences have been shown to have negative health outcomes in both physical and mental well-being. ${ }^{3,11}$ Therefore, we can conclude that the development of EI is essential during childhood 
because there is rapid emotional growth at this stage in life. ${ }^{1}$ Several studies have concluded that EI can be learned, honed, and improved by training parents. Parents are the key to the development of children's emotional and social skills. ${ }^{8}$ At this stage of childhood, several factors have been found to contribute to the development of EI. Several studies ${ }^{3,5,12}$ have found that parenting style, family structure and environment, childhood experiences, academic success, psychological health, and education programs impact children's EI.

In recent years, the Saudi educational system's major challenge has been improving the quality of education and producing globally competitive graduates. The government aims to provide their human resources with skills and intelligence that can match the demands of the labor market. Thus, the education sector in the Kingdom of Saudi Arabia is now focused on studies of EI and the academic achievements of gifted students. In Saudi Arabia, it is believed that education is a primary, essential factor for societal development. ${ }^{13}$ Consequently, the government is providing students with privileges and scholarships to serve their basic educational needs. One study emphasized that academic achievement is significant for gifted students because it is associated with positive outcomes in the future. ${ }^{7}$ It is hoped that this research will contribute to a deeper understanding of the link between personal characteristics, family characteristics and school performance and emotional intelligence among children in Saudi Arabia. However, the present study found that there are few studies applicable to EI, especially among children in Saudi Arabia. The commitment of the Saudi Arabia to the development of these students requires comprehensive research, particularly on the evaluation of the outcomes of their education programs. Thus, this study aimed to explore children's EI in the Saudi Arabia. Significant associations between EI and the personal characteristics, family characteristics, and school performance of Saudi children were investigated.

Methods. The study applied a quantitative approach using a cross-sectional design to collect and provide data at a defined time and describe the relationship between variables and EI in children. A sample of 684 students from 5 regions participated in the study by completing a survey questionnaire. Convenience

Disclosure. Authors have no conflict of interests, and the work was not supported or funded by any drug company. sampling methodologies were employed to draw a sample from the population who were close at hand and to draw on relationships that were easily accessed by the researcher. The inclusion criteria included students 1) registered in the basic education program, 2) identified as Saudi national, and 3) whose parents consented to participate in the survey. The exclusion criteria included students who were absent or could not complete the questionnaire for any reason. Participants were encouraged to answer the questions with the help of their parents, their teacher or the researcher, as necessary.

A self-administered questionnaire written in the Arabic language was used. It was composed of 2 parts. Part 1 included items on the students' school performance and personal and family characteristics. Part 2 assessed the participants' EI using a previously validated and reliable self-report short version of the instrument. Several studies have utilized the same scale to assess EI. One was conducted in another academic environment by Shuler, ${ }^{14}$ while others explored EI in an Arabic context. ${ }^{15,16}$ The scale is known as the BarOn Emotional Quotient Inventory-Youth Version or EQ-i: YV (S) and is composed of 30 items. The 4 subscales include Intrapersonal, Interpersonal, Stress Management, and Adaptability, which comprise 24 items. A 6-item Positive Impression scale, which is included in the original EQ-i: YV by Bar-On \& Parker (2000), was added to this study to better explore EI. ${ }^{17}$ Participants were instructed to respond to each item with never, sometimes, often, or very often true for them. The participants' responses were assigned numbers 1 to 4 . A combined technique was used as an appropriate method to maintain content equivalences between the original and translated instruments in international research. ${ }^{18}$ Thus, the instrument was translated into Arabic using forward-translation and back-translation techniques utilizing a combined technique. ${ }^{18}$ Then, 2 bilingual researchers blindly translated the instruments: one translated from English to Arabic, and the other backtranslated the questionnaire. A panel of 5 bilingual academic experts in nursing research reviewed the questionnaire and ensured its validity. A pretest with $(n=10)$ participants was conducted in which the clarity of the content to children was assessed and revised. A pilot study $(n=30)$ was then conducted to improve the feasibility, clarity and appropriateness of the questionnaire before proceeding to the main study. The results indicated acceptable reliability; Cronbach's alpha coefficient was 0.69 .

The central, northern, southern, eastern, and western regions of Saudi Arabia were covered in the 
recruitment of the study participants. The selected schools, which offered basic education programs for children in the regions, were considered as the research settings. The recruitment process had a long timeline, and early participants were asked to help the researchers identify other participants who met the inclusion criteria. Therefore, referrals were incorporated into the data collection procedure until the desired sample size of $>200$ by convenience sampling was obtained. The data collection was conducted from November 2016 to March 2017.

The principles of the Helsinki Declaration were applied. Confidentiality was ensured for the parents and the students. They were advised that their participation was voluntary with the right to withdraw at any time. They were also informed that there was no real or potential harm for the study participants and that data would only be released for research purposes. Ethical study approval was obtained from the Institutional Review Board (IRB) of King Saud University College of Medicine (Ref. No. 18/0180/IRB).

Data analysis. A descriptive correlational approach was used to describe the EI of Saudi children enrolled in either a primary or intermediate education program. The design was also used to determine the existence of a relationship between the participants' characteristics and performance with EI. The data were analyzed using the Statistical Package for Social Sciences (SPSS) version 21. Descriptive statistics were used to describe the categorical and quantitative outcome variables. Correlation coefficients were used to assess the strength and direction of the relationships between the study variables. Regression analysis was used to determine the predictors of children's EI. A p value of $<0.05$ was applied to determine statistical significance with 95\% confidence for differences in means and the precision of estimates. ${ }^{19}$

Results. As shown in Table 1, of the 5 regions, the majority $(37.9 \%)$ of participants were from the central region, which was well represented by students in Riyadh, Saudi Arabia. The participants were mostly 13-15 years of age (33\%) and had experienced occasional health problems $(87.9 \%)$. The majority lived together with both parents $(57.3 \%)$, while $42.6 \%$ lived with one parent. Regarding birth rank, from 1st to 13 th, the most significant numbers were first born $(24.3 \%)$. Nearly half of the mothers (45.6\%) and the fathers $(52.6 \%)$ had completed college, but more than half of the mothers $(62.4 \%)$ were not working, while the majority $(90.7 \%)$ of the fathers were employed.
Almost half of the participants (49.5\%) belonged to a family of more than 5 siblings and had a family income between 3,000-14,000 SAR.

Saudi Arabia follows a K-12 basic education system starting with primary education for 6 years, followed by intermediate and secondary education for 3 years each. The participants in the study were enrolled in either the primary $(44.7 \%)$ or intermediate (54\%) school. Most of them had an excellent $(63.2 \%)$ grade point average (GPA), and the majority (91\%) had no failing grade experiences. Of those who had failed, the majority failed only once (52.5\%); however, some children experienced failing grades more than twice (26.2\%).

Emotional intelligence. Table 2 presents the EI scores of the participants. It is apparent from this table that very few participants (4.4\%) scored in the highest range ( $>110$ ), and only $24.4 \%$ of the Saudi children demonstrated effective emotional and social functioning (scoring between 90-110). What is interesting about the data in this table is that the majority $(71.6 \%)$ of the participants obtained EI scores in the lowest range $(<90)($ mean $=83.2)$, which denotes minimal emotional and social skills.

Correlation between EI and the participants' profile. As shown in Table 3, only the father's educational level $(p=0.005)$ and income $(p=0.001)$ were significantly related to EI. Another important result of the study was a highly significant relationship between the southern region where the participants lived and their EI $(p=0.000)$. Moreover, there was a significant relationship between the father's employment status and the child's EI $(p=0.016)$. Additionally, a student who had failed a subject was more likely to have low EI ( $p=0.047)$.

Predictors of EI in children. The regression analysis showed that the identified independent variables were strong predictors of EI (Table 4). Variables that affected EI were mother's educational level, GPA, age, living with parents, physical health problems, father's educational level, frequency of failure and a working mother. Increased age and experiences of failure decreased children's EI. Having parents who do not live together can also decrease the level of EI of a child. Increased value of the mother's educational attainment decreased the child's EI. On the other hand, increased value of the father's educational attainment, GPA and freedom from health problems increased the level of EI. In summary, these results show that age $(p=0.001)$, living with parents $(p=0.005)$, mother's educational level $(p=0.001)$, GPA $(p=0.002)$ and health problems $(p=0.004)$ were shown to be strong predictors of EI. The overall model fit $R 2$ value was 0.554 , which implied that 
Table 1 - Profile characteristics of the participants.

\begin{tabular}{|c|c|c|}
\hline \multirow{2}{*}{$\begin{array}{l}\text { Variables } \\
\text { Indivual characteristics }\end{array}$} & \multirow[t]{2}{*}{$\mathrm{N}$} & \multirow[t]{2}{*}{$\%$} \\
\hline & & \\
\hline $\begin{array}{l}\text { Region } \\
\text { Central } \\
\text { Eastern } \\
\text { Western } \\
\text { Northern } \\
\text { Southern }\end{array}$ & $\begin{array}{r}253 \\
79 \\
201 \\
41 \\
93\end{array}$ & $\begin{array}{r}(37.9) \\
(11.8) \\
(30.1) \\
(6.1) \\
(13.9)\end{array}$ \\
\hline $\begin{array}{l}\text { Age (years) } \\
7-9 \\
10-12 \\
13-15 \\
>15\end{array}$ & $\begin{array}{l}115 \\
203 \\
226 \\
132\end{array}$ & $\begin{array}{l}(16.8) \\
(29.7) \\
(33.0) \\
(19.3)\end{array}$ \\
\hline $\begin{array}{l}\text { Health problems } \\
\text { Yes } \\
\text { No }\end{array}$ & $\begin{array}{r}576 \\
79\end{array}$ & $\begin{array}{l}(87.9) \\
(12.1)\end{array}$ \\
\hline $\begin{array}{l}\text { Family characteristics } \\
\text { Rank } \\
1^{\text {st }} \\
2^{\text {nd }} \\
3^{\text {rd }} \\
4^{\text {th }} \\
5^{\text {th }} \\
6^{\text {th }} \\
7^{\text {th }} \\
8^{\text {th }} \\
9^{\text {th }} \\
10^{\text {th }} \\
11^{\text {th }} \\
12^{\text {th }} \\
13^{\text {th }}\end{array}$ & $\begin{array}{r}163 \\
145 \\
116 \\
110 \\
83 \\
13 \\
11 \\
12 \\
6 \\
4 \\
4 \\
2 \\
1\end{array}$ & $\begin{array}{r}(24.3) \\
(21.6) \\
(17.3) \\
(16.4) \\
(12.4) \\
(1.9) \\
(1.6) \\
(1.8) \\
(0.9) \\
(0.6) \\
(0.6) \\
(0.3) \\
(0.1)\end{array}$ \\
\hline $\begin{array}{l}\text { Living with parents } \\
\text { Yes } \\
\text { No }\end{array}$ & $\begin{array}{l}329 \\
245\end{array}$ & $\begin{array}{l}(57.3) \\
(42.6)\end{array}$ \\
\hline $\begin{array}{l}\text { Educational level } \\
\text { Mother } \\
\text { Read and write only } \\
\text { Intermediate } \\
\text { High School } \\
\text { College and/or higher eduction }\end{array}$ & $\begin{array}{r}103 \\
83 \\
180 \\
307\end{array}$ & $\begin{array}{l}(15.3) \\
(12.3) \\
(26.7) \\
(45.6)\end{array}$ \\
\hline $\begin{array}{l}\text { Father } \\
\text { Read and Write Only } \\
\text { Intermediate } \\
\text { High School } \\
\text { College and/or higher eduction }\end{array}$ & $\begin{array}{r}72 \\
76 \\
167 \\
350\end{array}$ & $\begin{array}{l}(10.8) \\
(11.4) \\
(25.1) \\
(52.6)\end{array}$ \\
\hline $\begin{array}{l}\text { Working mothers } \\
\text { No } \\
\text { Yes }\end{array}$ & $\begin{array}{l}419 \\
252\end{array}$ & $\begin{array}{r}(62.4) \\
(37.6)\end{array}$ \\
\hline $\begin{array}{l}\text { Working fathers } \\
\text { No } \\
\text { Yes }\end{array}$ & $\begin{array}{r}64 \\
596\end{array}$ & $\begin{array}{r}(9.7) \\
(90.3)\end{array}$ \\
\hline $\begin{array}{l}\text { Family type } \\
\text { Father-mother-children fewer than } 5 \\
\text { Father-mother-children more than } 5 \\
\text { Father-mother-children-relatives }\end{array}$ & $\begin{array}{r}282 \\
324 \\
49\end{array}$ & $\begin{array}{r}(43.1) \\
(49.5) \\
(7.5)\end{array}$ \\
\hline $\begin{array}{l}\text { Family income } \\
<3,000 \text { SAR } \\
3,000-8,000 \text { SAR } \\
9,000-14,00 \text { SAR } \\
14,000-2,0000 \text { SAR } \\
>20,000 \text { SAR }\end{array}$ & $\begin{array}{r}45 \\
167 \\
167 \\
102 \\
617\end{array}$ & $\begin{array}{l}(7.3) \\
(27.1) \\
(27.1) \\
(16.5) \\
(22.0)\end{array}$ \\
\hline
\end{tabular}

Table 1 - Profile characteristics of the participants (continued).

\begin{tabular}{lrr}
\hline Academic characteristics & & \\
School & 293 & $(44.7)$ \\
Primary & 354 & $(54.0)$ \\
Intermediate & 9 & $(1.4)$ \\
No answer & & \\
GPA & 7 & $(1.0)$ \\
Weak & 61 & $(9.1)$ \\
Good & 178 & $(26.6)$ \\
Very Good & 423 & $(63.2)$ \\
Excellent & & \\
Did you fail? & 603 & $(91.0)$ \\
No & 60 & $(9.0)$ \\
Yes & & \\
Frequency of failure & 32 & $(52.5)$ \\
Once & 13 & $(21.3)$ \\
Twice & & \\
Three times or more & 16 & $(26.2)$ \\
\hline
\end{tabular}

Table 2 - Emotional intelligence (EI) scores.

\begin{tabular}{lrr}
\hline Scores & $\mathbf{n}$ & \multicolumn{1}{c}{$(\%)$} \\
\hline$<90$ & 490 & $(71.6)$ \\
$90-110$ & 164 & $(24.0)$ \\
$>110$ & 30 & $(4.4)$ \\
Total & 684 & $(100.0)$ \\
\hline
\end{tabular}

the predicted independent variables explained 55.4\% of the variability of dependent variable EI. Therefore, a child who has failing grades at a young age, lives with both parents, has a mother with a low educational level, and has no health problems; and a high GPA is likely to demonstrate high EI.

Discussion. Overall, these results suggest that children's characteristics, family characteristics, and academic performance affect the development of children's EI. The results of the current study revealed that among the factors examined in the correlation between EI and the participants' profile, statistically significant high correlations were found for region. Although the education system in Saudi Arabia is one system across the regions, a significant association was observed between students living in the southern region compared to those living in other regions. Thus, being from the southern region was highly linked to children's EI. Students from the southern region, which is considered the agricultural area, had higher EI. The southern region occupies a large area of mountains and farms and is a place where the children are entertained more by nature and less by technological advances. 
Table 3 - Relationship of the participants' characteristics and emotional intelligence (EI).

\begin{tabular}{lcc}
\hline $\begin{array}{l}\text { Participants' } \\
\text { characteristics }\end{array}$ & $\begin{array}{c}\text { Correlation coefficient }{ }^{\mathrm{a}} / \\
\text { Contingency coefficient }\end{array}$ & P-value \\
\hline Age & $-0.022^{\mathrm{a}}$ & 0.560 \\
School level & $0.039^{\mathrm{a}}$ & 0.323 \\
Rank & $-0.032^{\mathrm{a}}$ & 0.407 \\
Mother's educational & $0.068^{\mathrm{a}}$ & 0.078 \\
level & & \\
Father's educational & $0.109^{\mathrm{a}}$ & $0.005^{*}$ \\
level & & \\
Income & $0.137^{\mathrm{a}}$ & $0.001^{*}$ \\
GPA & $0.050^{\mathrm{a}}$ & 0.194 \\
Region & $0.310^{\mathrm{b}}$ & $0.000^{*}$ \\
Parents living & $-0.036^{\mathrm{b}}$ & 0.346 \\
together & & \\
Living with parents & $0.067^{\mathrm{b}}$ & 0.106 \\
Working mother & $-0.028^{\mathrm{b}}$ & 0.464 \\
Working father & $0.094^{\mathrm{b}}$ & $0.016^{*}$ \\
Failed subject & $-0.077^{\mathrm{b}}$ & $0.047^{*}$ \\
Physical health & $0.055^{\mathrm{b}}$ & 0.160 \\
problem & & \\
Type of family & $0.041^{\mathrm{b}}$ & 0.879 \\
\hline
\end{tabular}

Table 4 - Predictors of emotional intelligence (EI).

\begin{tabular}{lcc}
\hline Model & OR $(95 \%$ CI $)$ & $P$-value \\
\hline Age & $2.16(1.57-2.99)$ & $0.001^{*}$ \\
Living with parents & $2.07(1.51-2.86)$ & $0.005^{*}$ \\
Mother's educational level & $2.51(1.71-3.78)$ & $0.001^{*}$ \\
Father's educational level & $1.98(1.57-2.51)$ & $0.044^{*}$ \\
GPA & $2.42(1.65-3.61)$ & $0.002^{*}$ \\
Frequency of failure & $1.91(1.52-2.42)$ & $0.033^{*}$ \\
Physical health problem & $2.09(1.61-2.96)$ & $0.004^{*}$ \\
Working mother & $1.81(1.22-2.32)$ & $0.049^{*}$ \\
Working father & $1.04(0.99-1.08)$ & 0.072 \\
\hline \multicolumn{2}{c}{ OR - odds ratio, 95\% CI - 95\% confidence intervals, GPA - } \\
\hline
\end{tabular}

This finding suggests that the culture in which a child grows up affects the development of EI. Some studies have revealed that culture influences ways of expressing emotion. ${ }^{20,21}$ Current advances in technology have been accompanied by a specific deterioration in emotions, which is reflected in mental health deterioration. Hamissi et $\mathrm{al}^{22}$ identified an inverse relationship between the severity of technology use and the EI of students. Thus, exposing children to more natural areas will help them develop emotional and social functioning behaviors that are very important for children's EI.

Other factors that showed statistically significant positive correlations were father's educational level, working conditions, and family income. The higher the father's educational level and income, the better the EI of the child. A good educational background can provide an individual with better job opportunities a higher salary potential. Thus, the ability of the father to provide for the family can influence the improvement of the child's EI. Moreover, there was a significant relationship between the father's working conditions and the child's EI. This finding indicates that participants whose fathers are working tend to have low EI scores, suggesting that the presence of a father on a daily basis and the quality of time the father spends with the child can make a difference in improving the child's emotional and social skills. It appears that the father-child relationship is a significant factor in the development of social and EI among Saudi Arabian children. It seems that Saudi children are influenced by their fathers more than by their mothers. This finding may be due to the fact that Saudi Arabia is a maledominant culture, and children spend most of their time with their mother rather than their father, which may lead them to be more influenced by their mother. ${ }^{23}$ A recent study ${ }^{24}$ emphasized the strong foundation provided by parents for their child's health and well-being. In a study ${ }^{8}$ on perceived parenting styles and EI among Iranian male students, the findings revealed the importance of an early parent-child relationship that is a reflection of the culture. The authors added that an affectionate parenting style and parents who can provide for the basic needs of their children foster the development of self-confidence, emotional integrity, and self-regulation. Therefore, parents should spend time with their children and teach them skills to develop their emotional and social capabilities. The results of this study were consistent with the study by Harrod et $\mathrm{al},{ }^{25}$ which measured the EI of 200 children between 16 and 19 years old. A positive relationship was found between the educational levels of parents and household income. Fathers who have a high educational background have more significant opportunities to hold high-paying jobs and, in turn, can provide for their family. However, children with fathers who are working have been shown to have lower EI compared to those whose fathers are not working. In Saudi Arabia, men are accustomed to toiling for their family. Therefore, most individuals with jobs in the kingdom are fathers. This affects the quality time for fathers to bond with their children and to help them develop emotional and social skills. With this seemingly contradictory result, working fathers should strike a balance of spending quality time with their children while having to work. 
Academic achievement was also critical in the formulation of positive EI. In this study, children with no failing grades had higher EI compared to those who failed once in a year. Achievement can boost a child's self-image and confidence and simultaneously cultivate discipline and excellence within the child. ${ }^{26}$ This result is congruent with the study by Santiago, ${ }^{27}$ who concluded that the EI of intermediate pupils is significantly correlated with their academic achievement. Several studies, ${ }^{28-30}$ have shown positive outcomes of EI on the academic performance of children. These studies recommended developing the school's curriculum attention to EI to improve student learning and increase GPA.

The results showed that among theidentified variables, age, living with parents, father and mother's educational level, GPA, frequency of failure, a working mother, and freedom from health problems were predictors of EI. Individually, children who have the experience of failure at a young age and who suffer a failing grade at a young age are more able to adapt emotionally, thus acquiring the necessary emotional and social skills to develop EI. On the other hand, having parents who do not live together decreases the level of EI of a child. When a child is nurtured and cared for by parents, he or she can have a high level of EI, suggesting that parenting styles and quality time can improve the child's EI. Increased value of the mother's educational attainment decreased the child's EI, which suggests that mothers with higher educational attainment have a higher chance of acquiring a job and subsequently spending less time with their children. Having parents who are working decreases the EI level of a child. Working parents have less time with their children and cannot oversee their children's activities as often as they would like because of time constraints. An increase in GPA also increases EI because good academic performance in school fosters self-confidence and excellence. On the other hand, increasing the number of times the child fails decreases their EI. The more a child experiences failure, the more he will exhibit self-pity and lower self-esteem, which are associated with poor emotional and social skills. In addition, an increase in the incidence of health problems decreases a child's EI; therefore, having no health problems increases one's EI. The result for GPA is similar to that in the study by Allen, ${ }^{31}$ which showed that the cognitive intelligence of children impacted EI among 9 to 12 -year-old children. A study by Yahaya et $\mathrm{al}^{32}$ showed that children in secondary schools achieved better academic performance when they had better self-awareness, emotional management, and empathy, all of which are components of EI. Parents, such as fathers, can help children optimize their intelligence, such as EI, but the intellectual function is multifaceted and influenced by several other factors. ${ }^{33}$ The father's educational attainment implies better adaptability to help children optimize their skills and abilities, including managing their emotions. Pérez et $\mathrm{al}^{34}$ found that higher EI led to higher life satisfaction than lower EI. Therefore, life satisfaction is part of mental health, and people who lack emotional expression are inclined toward antisocial behaviors and mental illness. ${ }^{35}$ These findings raise intriguing questions regarding the nature and extent of children's emotional intelligence across regions.

Study limitations. The present study utilized convenience sampling in the selection of schools across regions and participants; thus, the results cannot be entirely generalized in Saudi Arabia. Using questionnaires, the students gave their responses as perceptions that may reflect their cultural practices and traditions. Participants' responses are also limited to what is prevalent in their actual settings. Participants who gave genuine responses to the questionnaires may have been those who were the most enthusiastic about participating.

In conclusion, considering the above results, this study concludes that personal characteristics, family characteristics and school performance interact to create an environment for emotional and social growth among children in basic education programs. The current study contributes to the understanding of EI among children in Saudi Arabia. These findings can be used in pediatric nursing and school health to enhance professional nursing practice and the quality of nursing care inclusive of children. This is especially important when counseling parents and their children on academic achievements, relationships with fellow students, and parent-child relationships. Teachers, school nurses and other healthcare providers who specialize in pediatric nursing and parenting are encouraged to investigate EI among Saudi children, especially in light of current technological advances that often disconnect them from their external environment.

Acknowledgment. The author is thankful to the Deanship of Scientific Research, College of Nursing Research Center at King Saud University, Riyadh, Saudi Arabia for funding this research.

\section{References}

1. Kushe C, Greenberg M. Brain development and emotionalsocial learning. In: Elias H, Arold H, editors. The Educator's Guide to Emotional Intelligence and Academic Achievement. London (UK): Corwin Press; 2006. p. 15-33. 
2. Morand DA. Family size and intelligence revisited: the role of emotional intelligence. Psychol Rep 1999; 84: 643-664.

3. Alaloom BB. Understanding the lived childhood experiences of Arab Americans with high emotional intelligence [dissertation]. Minneapolis (MN): Capella University; 2016.

4. Vaida S, Opre A. Emotional intelligence versus emotional competence. Journal of Psychological and Educational Research 2014; 22: 26-33.

5. Afzal M, Afzal M. Relationship of Family Structure and Emotional Intelligence of Secondary School Students in Islamabad. American Journal of Educational Research 2016; 4: 685-688. doi:10.12691.x

6. Freedman J, Jensen, A. A Case for Emotional Intelligence in Our Schools. Six seconds white paper. [cited 2017]. Available from URL: https://prodimages.6seconds.org/pdf/case_for_ EQ_school.pdf.

7. Faisal A. The influence of emotional intelligence towards academic achievement among gifted students in Saudi Arabia (Doctorate dissertation). Available from URL: http://eprints. usm.my/30397/1/AL-SAHAFI_FAISAL.pdf. 2016.

8. Abdollahi A, Talib M, Motalebi S. Perceived parenting styles and emotional intelligence among Iranian boy students. Asian Journal of Social Sciences and Humanities 2013; 2: 2186-8492.

9. Killian K. Development and validation of the emotional selfawareness questionnaire: A measure of emotional intelligence. Journal of Marital and Family Therapy 2012; 38: 502-514.

10. Freedman J, Morrison J, Olsson A. Leadership success and emotional intelligence in middle east. Six seconds white paper. Available from URL: https://www.academia.edu/1293110/ Leadership_Success_and_Emotional_Intelligen e_in_the_ Middle_East. 2010.

11. Lanoue M, Graeber D, Helitzer D, Fawcett J. Negative affect predicts adults' ratings of the current, but not childhood, impact of adverse childhood events. Community Mental Health Journal 2013; 49: 560-566.

12. Al-eed A. Emotional intelligence and its relationship to academic success when students of Arabic in the university of hail. Available from URL: http://www.iijoe.org/v4/ IIJOE_A_09_02_04_2015.pdf. 2015

13. Alqefari A. A study of programs for gifted students in the Kingdom of Saudi Arabia [dissertation]. London (UK): Brunel University; 2010.

14. Shuler CN. An analysis of the Emotional Quotient Inventory: Youth Version as a measure of emotional intelligence in children and adolescents. (Unpublished $\mathrm{PhD}$ thesis), The Florida State University. 2004.

15. Al-Milli S. Differences in emotional intelligence between gifted and normal students in Damascus: A field study of the first secondary class students in Damascus city. Damascus University Journal 2011; 27: 283-320. (Arabic).

16. Al-Qafaas WK. Validity of the bar-on emotional quotient inventory: youth version using both sides of the psychological adjustment. College of Education Journal, University of Benha. 2007; 17: 1-50. (Arabic).

17. Bar-On R, Parker JDA. The Bar-On Emotional Quotient Inventory: Youth Version (EQ-i:YV) Technical Manual. Toronto (Canada): Multi-Health Systems; 2002.

18. Cha ES, Kim KH, Erlen JA. Translation of scales in crosscultural research: Issues and techniques. J Adv Nurs 2007; 58 : 386-395.
19. Miles J, Shevlin M. Applying Regression and Correlation: A Guide for Students and Researchers. London: Sage; 2001.

20. Tanaka A, Koizumi A, Imai H, Hiramatsu S, Hiramoto E, de Gelder B. I feel your voice. Cultural differences in the multisensory perception of emotion. Source Cognitive and Affective Neuroscience Laboratory, Tilburg University. doi: 10.1177/0956797610380698. 2010.

21. Miyamoto Y, Ryff C. Cultural differences in the dialectical and non-dialectical emotional styles and their implications for health. Cognition and Emotion 2011; 25: 22-30.

22. Hamissi J, Babaie M, Hosseini M, Babaie F. The relationship between emotional intelligence and technology addiction among university students. International Journal of Collaborative Research on Internal Medicine \& Public Health 2013; 5: 310-319.

23. Marks J, Bun LC, McHale SM. Family Patterns of Gender Role Attitudes. Sex Roles 2009; 61: 221-234.

24. Chandran A, Nair B. Family climate as a predictor of emotional intelligence in adolescents. Journal of the Indian Academy of Applied Psychology. Available from URL: https://www.questia. $\mathrm{com} / \mathrm{read} / 1 \mathrm{P} 3-3648687491 /$ family-climate-as-a-predictor-ofemotional-intelligence.2015.

25. Harrod NR, Scheer SD. An exploration of adolescent emotional intelligence in relation to demographic characteristics. Adolescence 2005; 40: 159.

26. Di Fabio A, Kenny ME. Promoting emotional intelligence and career decision making among Italian high school students. Journal of Career Assessment 2011; 19: 21-34.

27. Santiago A. Emotional Intelligence and Academic Achievement of Intermediate Pupils. Theses. Available from URL: https:// www.academia.edu/3835706/Emotional_Intelligence_ Academic__Performance_of_Intermediate_Pupils_in_ CDLS?auto=download. 2010.

28. Mavroveli S, Sánchez-Ruiz MJ. Trait emotional intelligence influences on academic achievement and school behavior. British Journal of Educational Psychology 2011; 81: 112-134.

29. Parker JDA, Creque RE, Barnhart DL, Harris JI, Majeski SA, Wood LM, et al. Academic achievement in high school, does emotional intelligence matter? Personality and Individual Difference 2004; 37: 1321-1330.

30. Freedman J. Key lessons from 35 years of social-emotional education: How self-science builds self-awareness, positive relationships, and healthy decision-making. Perspectives in Education 2003; 21: 69-80.

31. Allen M. Investigating Emotional Intelligence in Children: Exploring its Relationship to Cognitive Intelligence. Master Theses. Western Kentucky University, USA. 2000.

32. Yahaya A, Ee NG, Bachok JD, Yahaya N, Boon Y, Hashim S, et al. The impact of emotional intelligence element on academic achievement. Archives Des Sciences 2012; 65: (4).

33. Biller H. Fathers and families; paternal factors in child development. USA: Greenwood Publishing Inc.; 1993.

34. Pérez-Escoda N, Albert, A. Does emotional intelligence moderate the relationship between satisfaction in specific domains and life satisfaction? International Journal of Psychology and Psychological Therapy.2016; 16: 131-140.

35. Richards KC, Campania C, Muse-Burke JL. Self-care and well-being in mental health professionals: the mediating effects of self-awareness and mindfulness. Journal of Mental Health Counseling 2010; 32: 247-264. 